\title{
Introduction
}

\section{How Individual and Environmental Factors affect Employment Outcomes}

\author{
Purvi Sevak $^{\mathrm{a}, *}$, David C. Stapleton ${ }^{\mathrm{a}}$ and John O’Neill ${ }^{\mathrm{b}}$ \\ ${ }^{a}$ Mathematica Policy Research, Princeton, NJ, USA \\ ${ }^{\mathrm{b}}$ Kessler Foundation, West Orange, NJ, USA
}

Revised/Accepted August 2016

State Vocational Rehabilitation (VR) agencies provide services to a diverse population of approximately one million people with disabilities annually (RSA, 2016) seeking support to achieve their independent living and employment goals. There is growing interest among policymakers and practitioners in improving the delivery of VR services to improve the recipients' long-term employment outcomes. Reflecting concerns of fiscal responsibility, there is also interest in measuring the return on investment of these services (Dean et al., 2014). The Workforce Investment Opportunity Act (WIOA) places a renewed emphasis on the role of state VR agencies in improving employment outcomes for individuals with disabilities. It has several goals that could alter how state VR agencies provide services to eligible applicants, including increased emphases on (1) competitive integrated employment and (2) serving transition-age youth.

One major challenge VR agencies must address when administering their programs in general, and implementing WIOA in particular, is the heterogeneity of their customers. Beyond obvious differences in the nature of their impairments, customers are diverse in terms of their education, skills, and other personal characteristics. In addition, customers' needs are

*Address for correspondence: Purvi Sevak, Mathematica Policy Research, P.O. Box 2393, Princeton, NJ 08543-2393, USA. Tel.: +1 609945 6596; Fax: +1 609799 0005; E-mail: psevak@ mathematica-mpr.com. dynamic; they change as their impairments evolve, as they learn to adapt to their impairments, as their support networks develop, and as they enter or exit other public or private programs. Finally, customers' needs and how VR agencies may address those needs are shaped by the local environment- the economic, programmatic, and physical features of their states and localities (Honeycutt et al., 2016; Stapleton et al., 2010; U.S. Government Accountability Office, 2005).

Understanding these individual and environmental factors and how they relate to VR outcomes can help administrators and counselors make decisions about how to best allocate services and resources to improve employment outcomes while satisfying the requirements of federal and state laws and regulations. For example, transition-age VR customers who have grown up with disabilities are more likely to need education, training, and other support that can help them obtain their first substantial job, whereas older customers who are experiencing disability for the first time are more likely to need to learn how they can manage or adapt to their new circumstances so they can return to work, stay at work, or get a better job. A VR agency's ability to meet the needs of these two types of clients depends on the agency's environment-jobs available in the local economy, policy changes such as WIOA, educational opportunities, the capabilities and accessibility of health and rehabilitation providers, the characteristics of public transportation, and so forth. 
Information about the characteristics of VR customers and how they relate to post-VR outcomes has generally been obtained from the individual case records in the Rehabilitation Services Administration-911 (RSA-911) data. The RSA-911 provides information on every case for every agency, but the data have several limitations; for example, a limited amount of information about each case is reported for administrative purposes, and outcome information is limited to status at the time of closure. The last nationwide survey of VR participants (the Longitudinal Study of the Vocational Rehabilitation Program) finished data collection in 2000 (Hayward $\&$ Schmidt-Davis, 2003). More current and complete information on the contextual factors that shape clients' needs and outcomes is needed.

The six articles in this volume of the Journal of Vocational Rehabilitation provide new evidence on the individual and environmental factors that are associated with employment and program participation of VR customers. The articles draw on findings using a combination of survey and administrative data to examine variation across VR subgroups, defined by characteristics at entry such as disability program status, age, education, impairment, and state. The volume includes findings from a literature review on factors that might influence VR outcomes, subgroup analyses using RSA-911 that have been matched at the individual level to Social Security Administration (SSA) data, and new data from the Survey of Disability and Employment (SDE) on applicant characteristics in three states (New Jersey, Mississippi, and Ohio).

The first article is a literature review of 14 studies that use individually matched RSA-SSA data to examine the relationship between employment services, mostly provided by VR agencies, and outcomes (Stapleton \& Martin). Stapleton and Martin find the literature successfully documents the characteristics of people who use VR services, as well as their employment and program outcomes, but it provides limited information about the impact of VR services on those outcomes. For instance, the findings reviewed indicate that, although most VR applicants do not receive SSA disability benefits, they are more likely to begin receiving SSA disability benefits if the VR agency cannot serve the applicants quickly. Additionally, SSA disability beneficiaries who enroll in services tend to increase their employment and modestly reduce their benefit dependency. The studies show that the characteristics and outcomes of VR customers vary widely across agencies, but they provide little information on the causes of such variation. For the most part, the studies do not provide unambiguous insights into the impact of VR services on employment and program outcomes because VR participants are self-selected. Because of this self-selection, it is not feasible to infer what the outcomes for the VR participants would have been in the absence of the services without external information. Nonetheless, the authors conclude that the matched data are valuable in providing contextual information on the diverse pathways to employment and program participation outcomes of people with disabilities. Additionally, they find that the data could be very useful for evaluating impacts of significant policy changes, such as those instigated by WIOA. They can also be used to support the evaluation of a well-designed demonstration effort, such as a current RSA demonstration that is using random assignment of supervisory units within two states to evaluate the impacts of service delivery innovations for VR applicants who are receiving Social Security Disability Insurance (SSDI) benefits. $^{1}$

The next three articles use RSA-911 data to provide new information on VR subgroups (Honeycutt et al., O'Neill et al.; and Mann et al.). Honeycutt et al. use matched RSA-911 data to track the young adult outcomes of transition-age youth VR applicants and participants, which is a subgroup of direct relevance in the WIOA legislation. The use of matched data in the analysis provides new long-term information on outcomes, given that state VR agencies do not track applicants for long after they stop receiving services. Honeycutt et al. track outcomes for VR applicants and participants for up to 10 years following their initial VR application. They find high school dropouts have the lowest odds of receiving services and employment closures. They also show that those who were still in high school at application have lower employment rates at closure than those who were working or in post-secondary school when they applied. These findings are particularly relevant to WIOA, given that states will now have to prioritize more youth who are presumably in school, and hence, have more school-based needs. For example, the efforts of VR agencies to increase services to transition-age youth could come at the expense of services to other VR subgroups who have high (or low) employment closure rates, so their aggregate closure rates could fall (or increase).

\footnotetext{
${ }^{1}$ See http://www2.ed.gov/about/offices/list/osers/rsa/ta-centers. html\#sga
} 
O'Neill et al. use the RSA-911 data to examine variation in competitive and non-competitive employment outcomes at the time of case closure by impairment subgroup. Differentiating competitive employment aligns with the strengthened focus in WIOA on competitive, integrated employment. They examine employment outcomes for 17 impairment groups identified in the RSA-911 data. They also explore the interactive effects of impairments with other characteristics, such as age, gender, and education, on employment. They find that the strong positive relationship between educational attainment and competitive employment varies substantially by impairment type. Similarly, the strong negative relationship between age and competitive employment varies across impairments. These differences underscore the importance of customized delivery of services that address potentially varied needs of different impairment groups throughout the life course.

Mann et al. use matched RSA-911 and SSA administrative records to examine the employment and program outcomes for VR applicants up to seven years after program exit. Again, the matched data are important in providing information on long-term outcomes. First, they demonstrate the influence of the local employment environment, which leads to poorer outcomes if the unemployment rate is higher, but also show that receipt of VR services mitigated that relationship. In addition, they show that VR participants who are employed when their VR case is closed have persistently higher employment outcomes seven years later than those who did not receive services. For example, those who received services and closed with employment were employed for about a third more years than those who did not receive VR services. Interestingly, SSDI nonbeneficiaries who were working at program exit were more likely than other VR applicants to eventually receive SSDI benefits. The results provide some valuable insights into how VR applicants might use services as a pathway to eventual employment and/or SSA program participation, underscoring the diversity of outcomes in the population. The correlation between employment status at closure and future outcomes provides an opportunity to target further assistance to VR customers as they leave the program.

The final two papers draw on information from the SDE (Jaszczak et al. and Brucker et al.). Jaszczak et al. describe the development and design of the SDE, and provide descriptive findings to motivate researchers to use the survey in future studies. One important objective in developing the SDE was to better understand the barriers and facilitators to employment that VR applicants face-concepts that the RSA-911 data do not capture. Jaszczak and coauthors find that most VR applicants have a strong interest in working, but report numerous health and social barriers to employment. For example, 86 percent of SDE respondents strongly agreed that they are or would be reliable workers. However, when asked why they are not currently working, two-thirds of respondents said that their health prevents them from doing so. Additionally, approximately half of the respondents said employers would not give them a chance and one-quarter stated that their friends or family discouraged work activity. Although the data reveal many such barriers to employment, they also reveal many facilitators to employment. A substantial number of respondents reported that they have received various accommodations, including help with physical demands, personal assistance, and modified work duties.

Brucker et al. examine perceived "social capital" as it relates to supporting employment among applicants for state VR. They define social capital as the availability of friends or family members who could provide help with finding a job; borrowing money to pay an urgent bill like electricity, gas, rent, or mortgage; transportation to get to work urgently; and help with a severe personal crisis that makes it difficult for them to find or keep a job. They find VR applicants are more likely to experience the presence of social capital in their lives if they report that they are currently working, have less severe disability, and have better perceived health. Given the significant links between social capital and outcomes, VR practitioners might find these measures particularly valuable in conducting needs assessments for their customers.

In summary, the articles in this special issue of the Journal of Vocational Rehabilitation highlight the diversity within the VR population-in terms of impairments, demographics, employment barriers, and social and other factors that could relate to long-term employment outcomes. The authors' administrative data findings indicate large differences in service receipt and outcomes across these groups, which may be particularly relevant to VR agencies given WIOA specifications to target services to select subgroups such as transition-age youth. State VR agency administrators might also find these new statistics on subgroups useful as they consider developing analytic models to target services to particular populations. Finally, the survey findings presented here provide insights into the barriers that VR prac- 
titioners must help their customers overcome and the social and workplace supports these customers draw on to gain and maintain employment success.

We want to thank the authors who contributed articles to this issue along with the National Institute on Disability, Independent Living, and Rehabilitation Research, which provided funding for the research described in these articles. We also want to thank Paul Wehman, the editor of the Journal of Vocational Rehabilitation, for the opportunity to disseminate this research in this forum.

\section{References}

Brucker, D., Botticello, A., O’Neill, J., \& Kutlik, A. (2017). Variations in social capital among vocational rehabilitation applicants. Journal of Vocational Rehabilitation, 46(2), 187-194.

Dean, D., Pepper, J. V., Schmidt, R. M., \& Stern, S. (2014). State vocational rehabilitation programs and federal disability insurance: An analysis of Virginia's vocational rehabilitation program. IZA Journal of Labor Policy, 3(1), 1-19.

Eckstein, A., Sevak, P., \& Wright, D. (2017). Personal characteristics of VR applicants: Findings from the Survey of Disability and Employment. Journal of Vocational Rehabilitation, 46(2), 177-185.

Hayward, B. J., \& Schmidt-Davis, H. (2003). Longitudinal study of the vocational rehabilitation services program. Final report 2: VR services and outcomes. Durham, NC: Research Triangle Institute.
Honeycutt, T., Martin, F., \& Wittenburg, D. (2017). Transitions and vocational rehabilitation success: Tracking outcomes for different types of youth. Journal of Vocational Rehabilitation, 46(2), 137-148.

Honeycutt, T., Thompkins, A., Bardos, M., \& Stern, S. (2016, online ahead of print). Youth with disabilities at the crossroads: The intersection of vocational rehabilitation and disability benefits for youth with disabilities. Rehabilitation Counseling Bulletin, 1-14.

Mann, D., Honeycutt, T., Bailey, M. S., \& O’Neill, J. (2017). Using administrative data to explore the employment and benefit receipt outcomes of vocational rehabilitation applicants years after program exit. Journal of Vocational Rehabilitation, 46(2), 159-176.

O’Neill, J., Kaczetow, W., Pfaller, J., \& Verkuilen, J. (2017). Impairment, demographics and competitive employment in vocational rehabilitation. Journal of Vocational Rehabilitation, 46(2), 149-158.

Rehabilitation Services Administration. (2016). Annual report fiscal year 2013. Report on federal activities under the Rehabilitation Act of 1973, as amended. U.S. Department of Education, Office of Special Education and Rehabilitation Services.

Stapleton, D., Honeycutt, T., \& Schechter, B. (2010). Closures are the tip of the iceberg: Exploring the variation in who receives state vocational rehabilitation services. Journal of Vocational Rehabilitation, 32(1), 61-76.

Stapleton, D. \& Martin, F. (2017). What have we learned using merged administrative data from SSA and RSA? Journal of Vocational Rehabilitation, 46(2), 121-136.

U.S. Government Accountability Office. (2005). Vocational rehabilitation: Better measures and monitoring could improve the performance of the VR program. (Report no. GAO-05-865). Washington, DC: U.S. GAO. 